ПЪЛНА ИНТЕРВЕНЦИОНАЛНА РЕВАСКУЛАРИЗАЦИЯ ИЛИ РЕВАСКУЛАРИЗАЦИЯ САМО НА ИНФАРКТНАТА АРТЕРИЯ ПРИ ПАЦИЕНТИ СЪС SТЕМІ - ЧАСТ І

\author{
И. Байрактарова и Е. Трендафилова \\ Национална кардиологична болнища - София
}

\title{
COMPLETE INTERVENTIONAL REVASCULARIZATION VERSUS INFARCT-RELATED ARTERY REVASCULARIZATION ONLY IN STEMI PATIENTS - PART I
}

\author{
I. Bayraktarova and E. Trendafilova \\ National Heart Hospital - Sofia
}

\begin{abstract}
Резюме. $\quad$ Многоклоновата коронарна болест е честа находка при пациентите, които получават интервенционално изследване и лечение по повод остър миокарден инфаркт със ST-елевация (STEMI). Оптималната терапевтична стратегия по отношение на инфарктната лезия е изяснена и е залегнала в редица ръководни правила. Подходът спрямо допълнителните значими коронарни лезии продължава да е обект на дебат и проучвания в световен мащаб както като обем на предприета интервенция, така и като времево позициониране спрямо индексното събитие.
\end{abstract}

Ключови думи: миокарден инфаркт със ST-елевация, интервенционална реваскуларизация, пълна реваскуларизация, многоклонова коронарна болест, терапевтични стратегии

Адрес д-р Искра Байрактарова, Клиника по кардиология, Национална кардиологична болница, ул. Коньовица № 65, за кореспонденция: 1309 София, e-mail: i.bayraktarova@yahoo.com

Abstract. Multivessel coronary artery disease is a frequent finding during primary PCl procedures in patients with ST-elevation myocardial infarction (STEMI). Optimal therapy of the infarct-related lesion has been largely elucidated and is stipulated in current guideline documents. Therapeutic options for the additional lesions are a subject of active debate and clinical trial worldwide - both the target degree of revascularization and its timing in relation to the index procedure remain unclear.

Key words: ST-elevation myocardial infarction, interventional revascularization, complete revascularization, multivessel disease, therapeutic strategies

Address Iskra Bayraktarova, MD, Cardiology Department, National Heart Hospital, 65 Konyovitsa St., BG - 1309 Sofia,

for correspondence: e-mail: i.bayraktarova@yahoo.com

\section{ВЪВЕДЕНИЕ}

В световен мащаб исхемичната болест на сърцето (ИБС) е най-честата причина за смърт и общата иे честота се увеличава. В Европа ежегодно над 1,8 млн. души загиват от последиците на ИБС, въпреки че сумарно смъртността от ИБС е с тенденция да намалява през последните 30 години. Разбира ce, тази статистика не може да се приложи без коментар за всички европейски държави еднакво, особено като се има предвид прилаганото разделение по региони при оценка на предстоящия риск
[1-3]. Реална статистика за България липсва. Относителната честота на острия миокарден инфраркт с персистираща елевация на ST-сегмента (STEMI) намалява, а на острия миокарден инфраркт (ОМИ) без персистираща елевация на ST-сегмента (NSTEMI) съответно се увеличава. Като абсолютни стойности честотата на STEMI намалява, а на NSTEMI се задържа стабилна. STEMI като цяло е по-често срещан при по-младите пациенти и при мъжете [2].

\section{"Отворената артерия"}

В настоящия момент максимално бързата и пълноценна реперфузия на инфраркт-свързаната 
артерия е препоръчваният и широко възприет модел на терапевтично поведение и може значимо да намали общата болестност и смъртност. Хипотезата за „отворената артерия“, предложена от Браунвалд през 80-те години на XX век [4], впоследствие подробно разгледана и потвърдена в редица проучвания [5], е преминала от първичната концепция за бързо възстановяване на кръвотока, през изисквания за отдалечен резултат [6] и понастоящем се развива в посока реперфузия на микроваскуларно ниво [7]. Ползите на „отворената“ артерия се простират отвъд количеството спасена миокардна тъкан, макар че този ефект е водещ [8]. При проследяване на ефектите от късната реваскуларизация се установява, че проходимата инфарктна артерия води до подобрено формиране на цикатрициалната тъкан и стабилизиране на слединфарктната зона, намалена слединфарктна експанзия и благоприятно ремоделиране, намален електрически нестабилитет и подобрен колатерален кръвоток към съседни зони, което допълнително благоприятства отдалечената прогноза [9].

Първичната перкутанна коронарна интервенция (пПКИ) е реперфузионен метод на избор при пациентите със STEMI [2], а също и при тези с NSTEMI, които подлежат на спешна или неотложна реваскуларизация след проведена съответна оценка на риска, както е описано в последните Препоръки [10]. В резултат пациентите с остър коронарен синдром, със или без налична ST-елевация, заемат немальк дял от общата популация пациенти, насочени за интервенционално лечение в ежедневната практика [11].

\section{КЛИНИЧНО ЗНАЧЕНИЕ НА МНОГОКЛОНОВАТА КОРОНАРНА БОЛЕСТ}

Известно е, че между 30 и 65\% от пациентите с остър коронарен синдром имат множество значими коронарни лезии [12-14]. Вътреболничната смъртност е съществено понижена при съвременна популация пациенти със STEMI. Въпреки това подгрупата пациенти с установена многоклонова коронарна болест (МКБ) и особено с придружаваща хронична тотална оклузия на коронарен съд имат съществено влошена отдалечена прогноза - по-висока смъртност и по-голяма честота на нов нефатален инфраркт, в сравнение с пациентите с едноклонова коронарна болест (1КБ). Като причини за разликата в отдалечените резултати могат да се обсъждат нестабилност на плаките в неинфарктните съдове, влошена миокардна перфузия и контрактилитет, персистираща остатъчна исхемия или просто по-тежък и агресивен атеросклеротичен процес при пациентите с МКБ [12, 15-17].
В проучването PROSPECT чрез вътресъдов ултразвук се изучава т.нар. виртуална хистология на съпътстващите лезии, описани при пациенти с остър коронарен синдром (ОКС), и се установява, че при половината плаки има значимо некротично ядро, което може да обясни нестабилния характер на тези лезии [18]. Очевидно е, че при пациенти с ОКС патофизиологичният процес не е ограничен в рамките на виновната лезия или виновния съд, а е сложен механичен, биохимичен и неврохуморален процес, който включва цялото коронарно съдово русло или дори цялата съдова система. Този по-глобален поглед върху ОКС е и в основата на прехода от концепцията за вулнерабилната плака към идеята за вулнерабилния пациент. Goldstein и сътр. [13] демонстрират, че при пациентите с ПКИ по повод ОКС често се откриват множество комплексни („нестабилни“) плаки.

Клиничното значение на МКБ при пациент със STEMI е изследвано и е ясно, че пациентите с МКБ имат значимо по-висок риск от сърдечно-съдова болестност и смъртност в сравнение с пациентите с 1КБ. При анализ на 253 пациенти с остър миокарден инфаркт Goldstein и сътр. [13] установяват значимо по-висока честота на повторен ОКС (19,0 спрямо $2,6 \%, p<0,001)$, повторна перкутанна интервенция (32,0 спрямо 12,4\%, p < 0,001), особено на „невиновни“ при първичния ОМИ лезии (17,0 спрямо $4,6 \%, p<0,001)$ и на проведена впоследствие аортокоронарна байпас хирургия (35,0 спрямо 11,1\%, p < 0,001) при налична МКБ в сравнение с 1КБ. До сходни изводи стигат и Corpus и сътр. [19], които анализират 820 пациенти с ОМИ и установяват, че в края на първата година пациентите с МКБ имат по-висока честота на реинфраркт (5,9 спрямо 1,6\%, p < 0,003), повторна реваскуларизация (18 спрямо 9,6\%, p < 0,001), смъртност (12 спрямо 3,2\%, p < 0,001) и големи сърдечно-съдови нежелани събития (MACE) (31 спрямо 13\%, p < 0,001) в сравнение с пациентите с едноклонова коронарна болест. Наличието на МКБ носи трикратно по-висок риск от смърт в края на първата година след прилагане на многовариантен модел за корекция на допълнителни изходни разлики (confounding factors) - OR 3,33, 95\% Cl 1,60-6,96, p < 0,0001.

Пациентите с МКБ и ОКС са с увеличен риск не само от сърдечно-съдова болестност, но и от сърдечно-съдова смъртност и от смърт по всякаква причина, в сравнение с тези с 1КБ. Патофизиологията на този увеличен риск не е съвсем изяснена. В серията проучвания TAMI 1-5 (Thrombolysis and Angioplasty in Myocardial Infarction) [12], пациентите с МКБ имат по-ниска левокамерна фрракция на изтласкване (ЛКФИ) при еднакъв размер на реализирания инфаркт в сравнение с едноклоновите 
пациенти. Тази по-ниска ФИ се отдава на значими разлики в кинетиката на неинфарктните зони в миокарда - докато при едноклоновите пациенти неинфарктните зони са хиперкинетични, при многоклоновите те често са нормо-, хипо- или дори дискинетични. Данните от TAMI отдават запазената фракция на изтласкване в острия момент основно на усилената контрактилност на неинфарктната зона, за която пък най-важният клиничен предсказващ фактор е отсъствието на значими лезии извън инфарктната [20]. Вътреболничната смъртност в посочените серии е основно зависима от функцията на неинфарктните зони, общата ЛКФИ и броя съдове със значими стенози, но не зависи от функцията на инфарктната зона. Следователно може да се заключи, че комбинацията от инфарктен и/или зашеметен миокард в инфактната зона (в резултат на запушената инфарктна артерия) и дисфункционален или хиберниран миокард в извънинфарктните зони (в резултат на придружаващи лезии) водят до неоптимална помпена функция в острия момент и последващи влошени клинични резултати. Нещо повече, известно е, че в условия на ОМИ кръвотокът в неинфарктните съдове може да е влошен и без конкретно наличие на значими стеснения, а в резултат на усилен системен възпалителен отговор и наличен вазоспазъм от увеличеното количество циркулиращи вазоактивни вещества [21]. Наличието на изходно значими стеснения на неинфарктните коронарни артерии, заедно с насложеното отрицателно въздействие на ОМИ върху цялостното коронарно кръвообращение, логично се свързват с още по-големи нарушения във функцията на неинфарктните зони. Глобалните кинетични нарушения са предпоставка за намалена ЛКФИ и увеличен риск от нежелани сърдечно-съдови събития.

Описаните наблюдения подчертават системния характер на „нестабилитета“ и предполагат, че пациентите с МКБ биха имали значима клинична полза от по-агресивни лечебни мерки, свързани не само с реканализация на виновната артерия, но и с подобряване на функцията на неинфарктните зони и съответно намаляване на отдалечената исхемия.

\section{ПЪЛНА РЕВАСКУЛАРИЗАЦИЯ С ПКИ ПРИ МКБ И STEMI - НЕРАНДОМИЗИРАНИ КЛИНИЧНИ ПРОУЧВАНИЯ}

Данните от малки, нерандомизирани проследявания и последвалите ги метаанализи са доста противоречиви относно ползата от многосъдовата перкутанна реваскуларизация при пациенти с МКБ и STEMI [22-25].

Теоретично има две основни гледни точки към подхода за пълна реваскуларизация. От една стра- на, потенциалните ползи на пълната реваскуларизация включват намаляване на риска от повторна исхемия и инфаркт чрез понижаване на общата исхемична тежест и подобряване на общата миокардна функция. Допълнителни ползи биха могли да се видят в редуцирания риск от кървене и съдови усложнения (при стратегия с провеждане на единствена едноетапна процедура), както и в потенциално по-ниски системни разходи. От друга страна, едноетапната процедура е теоретично свързана и със значим възможен риск с оглед по-трудната оценка на придружаващите лезии в условията на STEMI, множествено стентиране в условия на протромботичното инфарктно състояние и при активирана възпалителна каскада, възможността за остри усложнения при ангиопластиката на неинфарктни лезии (дисекация, нарушен кръвоток - slow/noreflow), по-висока радиационна доза, по-голямо количество контраст, свързано и с по-висок риск от контраст-индуцирана нефропатия, повишен цялостен риск в индексния болничен престой и повишена цена на индексния болничен престой [26]. Многоетапната стратегия за пълна реваскуларизация има недостатъка на многократните съдови достъпи, а при планови интервенции в рамките на различни хоспитализации - и завишена системна стойност.

Метаанализите, обобщаващи данните от проведени ретроспективни и кохортни проучвания, показват, че многосъдовата коронарна интервенция в условия на STEMI води до влошена вътреболнична преживяемост и до повишен риск от кървене, но се асоциира с по-нисък риск от реинфаркт и от повторна интервенция при сходна честота на големите нежелани сърдечно-съдови събития (MACE) [22, 23]. Редно е да се отбележи, че проследяванията, включени в посочените метаанализи, са доста разнородни, някои обхващат пациенти с кардиогенен шок (КШ), за други той е изключващ критерий. Пациентите с едномоментна пълна реваскуларизация са били по-често с КШ и с преден инфаркт и по-често са получили терапия с гликопротеинен IIbIIla инхибитор, което неминуемо оказва ефект върху цитираните резултати за смъртност и кървене.

Терапевтични разлики, водещи до изкривена интерпретация, се установяват и от Cavender и сътр. [27], които анализират 28936 пациенти със STEMI в Националния сърдечно-съдов регистър на САЩ (National Cardiovascular Data Registry), като установяват повишена болнична смъртност за едномоментната пълна реваскуларизация, която спира да бъде статистически значима след внимателна статистическа компенсация на базовите различия. В противовес, Qarawani и сътр. [28] докладват добре подбрани по сходни изходни показатели групи пациенти и наблюдават сходна смъртност в края на 
първата година, при намалена честота за големите нежелани събития в полза на пациентите, получили пълна едноетапна реваскуларизация.

При сравнението на реваскуларизация само на инфаркт-свързаната артерия с пълна едноетапна реваскуларизация или пълна отложена реваскуларизация, в метаанализите [24, 25] се установява, че пълната отложена реваскуларизация води както до понижена вътреболнична и 30-дневна смъртност [25], така и до подобрена дългосрочна преживяемост [24]. От друга страна, анализите оборват и идеята за повишен риск от отложена процедура на придружаващите лезии [29], като заключението е, че многосъдовата процедура е безопасна, но има значимо противоречие в получаваните данни за кратко- и дългосрочна преживяемост и полза, с оглед на което са необходими истински рандомизирани клинични проучвания. Всички цитирани метаанализи отбелязват и липсата на достатъчно информация за оптималния момент за провеждане на отложената реваскуларизация - дали в рамките на индексната хоспитализация, или след това, и ако е след това, в какъв времеви прозорец да се осъществи.

\section{ПЪЛНА РЕВАСКУЛАРИЗАЦИЯ С ПКИ ПРИ МКБ И STEMI - РАНДОМИЗИРАНИ КЛИНИЧНИ ПРОУЧВАНИЯ}

Първото рандомизирано проучване, сравняващо трите основни реваскуларизационни стратегии, проведено от Politi и сътр. [30], включва общо 214 пациенти, разделени в три рамена, като методът на неограничена рандомизация впоследствие получава критики, тъй като рамената не са добре балансирани - 84 пациенти са получили реваскуларизация само на инфарктния съд, 65 са получили едноетапна пълна реваскуларизация и 65 - пълна реваскуларизация на втори етап, средно 56,8 \pm 12,9 дни след индексната процедура. Авторите проследяват като първични крайни цели вътреболнична смърт, сърдечна смърт, смърт по каквато и да е причина, повторен остър коронарен синдром или повторна непланирана реваскуларизационна процедура. Изследването установява, че пациентите с пълна реваскуларизация независимо дали едномоментна, или отложена нямат допълнителен процедурен риск, а имат по-нисък риск от последващи големи нежелани сърдечно-съдови събития (МАCE), без да има значима разлика между двата типа пълна реваскуларизация по време на средно проследяване от 2,5 години. Важно е да се отбележи, че авторите са проследили честотата на контраст-индуцираната нефропатия в трите групи, както и на продължителността на болничния престой, като и двата параметъра нямат значима разлика между групите.
Резултатите от рандомизираното мултицентрово клинично проучване PRAMI (Preventive Angioplasty in Myocardial Infarction) [31] са публикувани прец 2013 г., а проучването е проведено през периода 2008-2013 г. в центрове във Великобритания и е включило 465 пациенти със STEMI. Пациентите са рандомизирани след успешна интервенция на инфарктния съд в две рамена - едноетапно продължаване към пълна реваскуларизация (234 пациенти) или приключване на процедурата до ниво реваскуларизиран инфарктен съд (231 пациенти). Пациенти със значима стволова стеноза ( $\geq 50 \%)$, с еквивалент на ствол, с предшестваща проведена хирургична реваскуларизация, с хронична пълна оклузия на неинфарктен съд или с кардиогенен шок са били изключени преди рандомизацията. Проследяването е продължило средно 23 месеца. Честотата на сърдечна смърт, нефатален нов инфаркт или неовладяема ангина са по-ниски в групата с осъществена пълна едноетапна реваскуларизация. Намалението е статистически значимо за нефатален инфаркт (HR 0,32, 95\% Cl 0,13-0,75, p= 0,009) и неовладяема ангина (HR 0,35, 95\% Cl 0,18-0,69, p = 0,002), но не и за сърдечна смърт (HR 0,34, 95\% Cl $0,11-1,08, p=0,07)$. Повторната реваскуларизация е по-рядка в групата с проведена пълна реваскуларизация (HR 0,30, 95\% Cl 0,17-0,56, p < 0,001), но няма разлика в честотата на несърдечната смърт (HR 1,10, 95\% Cl 0,38-3,18, p=0,86). Честотата на процедурните усложнения, включително перипроцедурен инсулт; кървене, изискващо кръвопреливане или хирургия, и контраст-индуцирана нефропатия, налагаща диализа, са сходни в двете групи ( $p=0,84)$. Процедурното време, фрлуороскопската доза и използваното количество контраст са логично по-високи в групата с пълна реваскуларизация.

CvLPRIT (Complete vs Lesion-only PRImary PCI Trial) [32] е отворено, мултицентрово рандомизирано клинично проучване, също проведено във Великобритания, като пациенти са набрани в периода 2011-2013 г. и са проследени 12 месеца. Включени са 296 поредни пациенти със STEMI, като са изключени лицата с предшестващ МИ с оформен Q-зъбец, предшестваща хирургична реваскуларизация, с кардиогенен шок или известно тежко хронично бъбречно заболяване, както и пациенти, които са противопоказани за многосъдова интервенция според преценката на оператора. Рандомизацията е проведена след ангиографията и преди реваскуларизацията на инфарктния съд, като 150 пациенти са попаднали в групата с пълна реваскуларизация (срещу 146 в другата група). Рандомизацията е стратифицирана според тип инфаркт (преден/различен от преден) и времето от началото на симптомите (< 3 часа/> 3 часа). Операторите са насърчени да 
проведат пълната реваскуларизация в рамките на първичната процедура с цел намаляване на повторните съдови достъпи, продължителността на болничния престой и риска за отпадане на пациенти поради оттегляне на съгласие. По клинични съображения е допускано отложено провеждане на пълната реваскуларизация, но задължително в рамките на индексния болничен престой. Първичната крайна цел в проучването е представена като сбор от смърт по всякаква причина, повторен МИ, сърдечна недостатъчност $(\mathrm{CH})$ или повторна реваскуларизация в рамките на първата година. Вторичните крайни точки изследват безопасността - исхемичен мозъчен инсулт, вътречерепно кървене, голямо невътречерепно кървене или усложнения на съдовия достъп, изискващи хирургия. Големите сърдечно-съдови събития (MACE) са значимо по-малко в групата с пълна реваскуларизация (10\%) в сравнение с групата с реваскуларизация само на инфарктна артерия (21,2\%; HR 0,45, 95\% Cl 0,24-0,84, p = $0,009)$. Разделянето на кривите настъпва рано - $p$ = 0,055 на 30-ия ден. Има и тенденция за по-ниски честоти на отделните компоненти на крайната точка и за сърдечно-съдовата смъртност в рамото с пълна реваскуларизация, но не се достига статистическа значимост, вероятно поради недостатъчния брой пациенти. Честотата на перипроцедурен инсулт, голямо кървене или контраст-индуцирана нефропатия са сравними в двете рамена. Процедурното време и използваният контраст са значимо повече в рамото с пълна реваскуларизация.

Подгрупов анализ на проучването описва особена полза за пациентите от женски пол, за тези над 65 години и за пациентите с двуклонова коронарна болест, макар че този тип анализ е спорен в подобна малка група пациенти. Важно е да се отбележи, че при 2/3 от пациентите, получили пълна реваскуларизация, тя е била едноетапна в рамките на индексната процедура, а при останалите е била в рамките на първичния болничен престой. Въпреки че авторите съобщават за изразена тенденция към подобрени клинични резултати на пациентите с едноетапна пълна реваскуларизация, не могат да се достигнат сигурни изводи с оглед на факта, че разделянето на тези две подгрупи е било базирано на клиничната преценка на операторите.

DANAMI-3 PRIMULTI [33] е отворено рандомизирано клинично проучване, част от по-голямата DANAMI-3 програма, проведена в две университетски болници в Дания. Включени са общо 627 пациенти за периода 2011-2014 г., като изключващи критерии са били кардиогенен шок, установени показания за хирургична реваскуларизация, бъбречна недостатъчност и неоптимален интервенционален резултат в инфарктния съд. Пациентите са рандомизирани след успешна първична интервенция на инфактната артерия в две рамена - 313 са рандомизирани да не получат допълнителна реваскуларизация, а останалите 314 попадат в групата за пълна отложена реваскуларизация. След средно 2 дни пациентите във втората група получават повторна интервенция, по време на която допълнителните лезии, установени в контекста на инфаркта, са оценени за функционална значимост c FFR (fractional flow reserve). Ако лезиите са преценена като функционално значими (FFR $<0,8)$, бива проведена пълна реваскуларизация. От всички пациенти в групата за пълна реваскуларизация 97 (31\%) са c FFR > 0,8 и не получават по-нататъшна интервенционална терапия. Първичната крайна точка (комбинация от смърт, нефатален МИ или исхемия-обусловена реваскуларизация) е достигната при 68 (22\%) от пациентите в рамото с чиста първична ПКИ и при 40 (13\%) от рандомизираните за пълна реваскуларизация (HR 0,56, 95\% Cl $0,38-0,83, p=0,004)$. Тази разлика е обусловена от по-ниска честота на повторната реваскуларизация (69\% намаление на необходимостта от повторна реваскуларизация) в рамото с пълна отложена реваскуларизация. Няма значими различия между групите по отношение на нефатален нов инфаркт или смъртност. Необходимостта както от спешна, така и от планова ПКИ на неинфарктните артерии, е по-ниска в групата с проведена пълна реваскуларизация. Няма разлики в перипроцедурните усложнения между двете групи.

Следващо значимо проучване, анализиращо пълната реваскуларизация в условия на STEMI, e COMPARE-ACUTE [34] - рандомизирано проучване с прилагане на FFR насочена пълна реваскуларизация. Рандомизирани са 885 пациенти в периода 2011-2015 г. в две групи в съотношение 2:1, като 590 пациенти са разпределени да получат интервенционално лечение единствено на инфаркт-свързаната артерия и 295 - пълна реваскуларизация след FFR в рамките на индексната процедура. По преценка на оператора е позволено пълната реваскуларизация да се отложи, но препоръчително не повече от 72 часа или най-късно до края на индексната хоспитализация. Всички пациенти, независимо от рандомизационния им статус, са получили FFR оценка на допълнителните лезии след провеждането на първичната интервенция на инфарктната артерия, с изключение на 18 души - 3-ма в групата с пълна реваскуларизация и 15 от групата с реваскуларизация само на инфарктната артерия. Разпределението на участниците според резултатите от FFR оценката е сравнимо в двете групи. Пациентите в групата, получила само реваскуларизация, и техните лекуващи лекари са имали информацията от ангиографи- 
ята, но не и от FFR оценката. Плановата отложена допълнителна реваскуларизация при тези пациенти, преценена като необходима от лекуващия им лекар и проведена в рамките на 45 дни, не е отбелязана като събитие, но спешните реваскуларизации, наложили се през същия период, са преброени като нови събития. Не са включени болните със стволова стеноза, хронична оклузия на неинфарктна артерия, повече от една артерия с влошен кръвоток, неоптимален резултат след интервенцията на инфарктната артерия, както и пациент с Килип клас III и IV (белодробен едем и шок). Важно е да се отбележи наличието на две FFR свързани усложнения в групата с реваскуларизация само на инфарктната артерия, като едното е довело до фатален изход, а другото - до перипроцедурен STEMI. В първичната крайна точка са включени смърт по каквато и да е причина, нов миокарден инфаркт, нова реваскуларизация (без посоченото изключение) и мозъчносъдово събитие. Вторичните крайни точки представляват нетен сбор на всички нежелани клинични събития (смърт, реваскуларизация, кървене, инфаркт, инсулт), каквато и да е било реваскуларизация (включително и проведените в рамките на 45-дневния период), голямо кървене, каквото и да е кървене, хоспитализация за нестабилна ангина, гръдна болка или прояви на $\mathrm{CH}$, както и стент-тромбоза. В края на първата година първичната крайна точка са достигнали 23-ма пациенти $(7,8 \%)$ от групата с пълна реваскуларизация и 121 пациенти $(20,5 \%)$ от групата с реваскуларизация само на инфарктната артерия (HR 0,35, 95\% Cl, 0,22-0,55, $\mathrm{p}<0,001)$. Разликата се дължи основно на повечето реваскуларизации, направени в групата с третирана само инфарктна артерия - около 1/3 като лечение на нестабилна и 1/3 като лечение на стабилна ангина. Отделните компоненти на първичната крайна цел не достигат самостоятелно до прага на статистическата значимост. Пациентите, получили едноетапна пълна реваскуларизация, са получили средно $22 \mathrm{ml}$ повече контраст и 6 минути по-дълга процедура, като и двете стойности са статистически значими.

Най-новото публикувано рандомизирано проучване е COMPLETE (Complete versus Culprit-Only Revascularization Strategies to Treat Multivessel Disease after Early Percutaneous Coronary Intervention [PCI] for STEMI) на Mehta и съавт. [35, 36]. Включени са 4041 пациенти със STEMI, които нямат предшестваща оперативна реваскуларизация или планирана такава и са без данни за КШ. Те са рандомизирани в две рамена - за реваскуларизация само на инфакт-свързаната артерия (2025 пациенти) или за пълна реваскуларизация (2016 пациенти). По преценка на оператора пълната ре- васкуларизация е в рамките на същия болничен престой (при 1285 пациенти, средно 1 ден след индексната реваскуларизация на инфарктната артерия) или планово след дехоспитализацията, но след не повече от 45 дни (при 596 пациенти, средно след 23 дни). Проучването е първото, което включва достатъчно пациенти, за да може достоверно да отчете като първични крайни точки смърт и нов инфаркт. Прехвърлянето между рандомизираните групи (cross-over rate) е под 5\% и за двете групи (съответно 4,7\% от групата с ПКИ само на инфактната артерия към пълна ПКИ и 3,9\% в обратна посока). Пациентите са набрани от февруари 2013 г. до март 2017 г. в 140 центъра и са проследени средно три години за комбинирана първична крайна точка от сърдечно-съдова смърт, нефатален МИ, със или без нова исхемия-обусловена реваскуларизация. Вторичните крайни точки включват първичните плюс изява на стенокардия или висок фрункционален клас сърдечна недостатъчност. Като крайни точки за безопасност са отчетени честота на инсулт, стент-тромбоза, значимо кървене или изява на остра контраст-индуцирана бъбречна увреда в двете групи. При отчитане на „придружаващата“ коронарна болест авторите се доверяват на ангиографската находка за лезии, които са над 80\% при визуална оценка, и използват допълнителни функционални методики, за да верифицират тежестта на т.нар. „гранични“ лезии в диапазона 60-80\% според визуалната оценка. Авторите установяват значимо по-ниски честоти на първичната крайна точка при пациентите с проведена пълна реваскуларизация - при 158 пациенти (7,8\%) спрямо 213 пациенти $(10,5 \%)$ в групата с реваскуларизация само на инфарктната артерия (HR 0,74, 95\% Cl, 0,60 до 0,91, p = 0,004), като тези резултати се дължат основно на намалена честота на нов реализиран инфаркт както STEMI, така и NSTEMI, в пълно реваскуларизараната група. При отчитане на новите исхемия-обусловени реваскуларизации първичната крайна цел е достигната при 179 пациенти (8,9\%) в групата с пълна реваскуларизация и при $339(16,7 \%)$ в групата с реваскуларизация само на инфарктната артерия (HR 0,51, 95\% Cl, 0,43-0,61, p < 0,001). Няма съществена разлика в риска от инсулт, голямо кървене или стент-тромбоза между двете групи, но в групата с пълна реваскуларизация значимо по-често се наблюдава остра контраст-индуцирана бъбречна увреда, като всички описани такива случаи са в подгрупата, получила пълна реваскуларизация в рамките на индексната хоспитализация. Авторите не установяват разлика в представени резултати, независимо от момента на пълната реваскуларизация - по време на индексната хоспитализация 
или след нея. Няма разлики и при поданализи в множество разгледани субпопулации пациенти.

\section{ОБСъЖДАНЕ И ИЗВОДИ}

Пациентите със STEMI в около половината от случаите са и пациенти с многоклонова коронарна болест. Основните терапевнични модели на поведение са три - реваскуларизация само на инфарктната артерия, реваскуларизация на всички съдове веднага и реваскуларизация на инфактната артерия заедно с отложена пълна реваскуларизация, като отлагането може да е в различен срок - от дни до месеци. Потенциалните ползи от пълната реваскуларизация трябва да се премерят срещу потенциалните рискове от допълителните интервенции, независимо дали със или без функционални изследвания на кръвотока, на един или няколко етапа.

За разлика от обсъдените рандомизирани клинични проучвания, предшествалите ги наблюдения установяват възможна вреда от провеждането на едноетапна пълна реваскуларизация [37]. Това може да се отдаде на напредналата междувременно интервенционална технология и разлики в проведените процедури, а също и на разлики в изходните параметри на изследваните пациенти. С оглед на известните недостатъци на обсервационните серии е възможно наблюденията да отразяват резултатите при например една по-тежко засегната от придружаващи заболявания популация, а не ефекта на самия терапевтичен модел. От друга страна, ретроспективните проучвания са податливи на много допълнителни объркващи фактори, което прави докладваните наблюдения по-малко надеждни.

Рандомизираните клинични проучвания носят изключително ценна информация относно безопасността и потенциалните ползи от пълната реваскуларизация, но всички те имат няколко сериозни недостатъка. Само едно от тях (COMPLETE) е достатъчно голямо, за да проследи т.нар. „твърди“ крайни точки, а именно смърт и нов миокарден инфаркт [36]. PRAMI е първично планирано да набере 600 пациенти, но е спряно предварително, след като междинен анализ показва полза от превантивната пълна реваскуларизация [31]. В резултат не може да се изключи вероятността това да е довело до преувеличаване на ползата от пълната реваскуларизация. В COMPLETE е заложена значимо по-голяма група пациенти, но с оглед на включващите и най-вече изключващите критерии е селектирана една нискорискова група пациенти с обща смъртност при проследяването около 1\% на година.

Както в PRAMI, така и в CVLPRIT, решението за значимостта на придружаващите лезии се базира единствено на ангиографската оценка [31, 32]. В острия момент на STEMI е известно, че дифузният коронарен спазъм не е рядкост, което би могло да доведе до надценяване на лезии, които не биха наложили реваскуларизация при последваща оценка, и съответно - до ненужни интервенции [38]. DANAMI-3 PRIMULTI установява, че FFR базираната оценка на втори етап води до най-добри отдалечени резултати, което е еднопосочно както с резултатите от PRAMI и CVLPRIT, така и с тези от някои по-стари обсервационни проследявания [24, 31-33]. Със сигурност приложението на функционална оценка на лезиите води до по-физиологична преценка на тяхната тежест. С оглед на съществуващите наблюдения за нарушена микроваскуларна функция в отдалечени от инфаркта зони дори месеци след самия остър момент [39], би могло да съществува известно съмнение, че в условия на STEMI стойностите на FFR могат да са недостоверни - притеснение, което в още по-голяма степен може да се приложи за COMPARE-ACUTE [34]. Въпреки наличието на съвременни наблюдения, които отхвърлят концепцията, че провеждането на FFR в инфарктни условия би било недостоверно [40], честотата на функционално несигнификантни лезии за популацията, докладвана в COMPAREACUTE (FFR в момента на първичната ПКИ), е значително по-голяма (434/867 изследвани, или $50 \%$ в сравнение с честотата на функционално несигнификантни лезии, докладвана в DANAMI-3 PRIMULTI (97/314 изследвани, или 31\%) по време на втора процедура, средно 2 дни след първичната. В този смисъл и с оглед на реалната клинична практика стратегията, заложена в COMPLETE - провеждане на функционална оценка само при пациенти с т.нар „гранични“ лезии, които в проучването са стенози от $60-80 \%$, и приемане на визуалната оценка за достоверна при стенози над 80\%, където има по-добро припокриване на резултатите от различните оценки, изглежда потенциално най-информативна и смислена.

Продължава да съществува известна неяснота относно по-благоприятния момент за провеждане на евентуална пълна реваскуларизация - незабавно или след недобре дефиниран срок на отлагане, в рамките на същата хоспитализация или при планирана последваща. Отложената пълна реваскуларизация изглежда по-удачна в по-старите метаанализи, а и е подкрепена от нови рандомизирани проучвания, за разлика от едноетапната, при която проучванията са в конфликт с по-старите данни. COMPLETE също натежава в посока на известно изчакване, като авторите не намират разлика в подгрупите пациенти, получили пълна реваскуларизация в рамките на същия болничен престой или няколко седмици след това. 
Промененият клас на препоръка в последните Препоръки на Европейското дружество по кардиология [2] отразява увеличаващите се доказателства, че пълната реваскуларизация носи ползи на пациентите със STEMI. От друга страна, остава разбирането, че такъв подход може би няма да е от полза за всички пациенти и следва да се проведе индивидуална оценка полза/риск в контекста на реалната клинична ситуация, която да включва тежестта на придружаващите лезии, риска от контраст-индуцирана нефропатия и оценка на остатъчната исхемия. Със сигурност провеждането на нови големи рандомизирани проучвания с включени достатъчно пациенти, за да отговорят на въпросите за твърдите крайни точки, а може би и дизайн в три рамена, както при Politi и сътр. [30], биха допринесли за изясняване на съществуващите в момента въпроси. В този смисъл резултатите на рандомизираното отворено клинично проучване COMPLETE са изключително интересни и ценни за клиничната практика, въпреки че остава въпросът дали резултатите на силно селектирана нискорискова група пациенти лесно ще се приложат за широкия спектър на реалната пациентна популация.

На фона на резултатите от световната интервенционална практика реалността в България остава неясна. Известно е, че преобладаващата част от рисковата тежест за развитие на сърдечно-съдовите заболявания се дължи на модифицируеми, но все по-широко разпространени рискови фрактори, свързани с начина на живот в съвременното общество [3, 41, 42]. Вероятно някои рискови фактори, като например тютюнопушенето, са далеч по-разпространени в България [43, 44]. В контраст с широкодостъпната и добре разработена интервенционална мрежа с установени практики за първична ПКИ, проследяването на нашите като цяло високорискови пациенти впоследствие е неясно. Дългосрочният ефрект от предприетите интервенционални терапевтични стратегии също остава с въпросителна [45-47]. У нас поетапната планова реваскуларизация безспорно е част от рутинната практика, особено в големите центрове и в нискорисковите популации пациенти. Проследените и публикувани резултати за тази актуална за нас популация, включваща вероятно по-широк рисков спектър пациенти в сравнение с рандомизираните проучвания в световен мащаб, са все още епизодични и оскъдни [47-49]. Установяването на тенденциите, успехите и пропуските в локалната клинична практика е съществена стъпка в изготвянето на прицелни здравни политики, както и в насочване на усилията на специалистите към ефективни терапевтични подходи при проследяването на пациентите с преживян STEMI.

\section{ЗАКЛЮЧЕНИЕ}

Натрупват се все повече положителни данни от рандомизирани проучвания за ползата от пълна реваскуларизация при добре селектирани многоклонови пациенти със STEMI. Предстои да се изясни доколко тези наблюдения важат за реалната пациентска популация в съвременната клинична практика. С оглед оскъдните за момента български данни в тази насока и вероятно по-тежкия рисков профил на нашите пациенти, следва да се направи опит за оценка на ефекта на масово прилаганите у нас терапевтични стратегии в тази група пациенти.

Не е деклариран конфрликт на интереси

\section{Библиография}

1. Piepoli M, Hoes A, Agewall S, et al. European Guidelines on cardiovascular disease prevention in clinical practice: The Sixth Joint Task Force of the ESC and Other Societies on Cardiovascular Disease Prevention in Clinical Practice. Eur Heart J, 2016;37(29):2315-81.

2. Ibanez B, James S, Agewell S, et al. ESC Guidelines for the management of acute myocardial infarction in patients presenting with ST-segment elevation: The Task Force for the management of acute myocardial infarction in patients presenting with ST-segment elevation of the ESC. Eur Heart J, 2017;29(2):1-66.

3. Mann DL, Zipes DP, Libby P, et al. Braunwald's Heart Disease: a Textbook of Cardiovascular Medicine, Philadelphia, Elsevier/ Saunders, 2015.

4. Braunwald E. Myocardial reperfusion, limitation of infarct size, reduction of left ventricular dysfunction, and improved survival. Should the paradigm be expanded? Circulation, 1989;79(2):441-4.

5. Califf R. The GUSTO trial and the open artery theory. Eur Heart J, 1997;18(F):2-10.

6. Geraci $E$ and Tognoni G. The Open Infarct-Related Artery Theory: A Critical View. Eur J Prev Cardiol, 1994;1(4):301-9.

7. Carvalho $C$. Microvascular reperfusion in myocardial infarction: The new concept of the open artery in the 21 st century. Rev Port Cardiol, 2017;36(10):743-5.

8. Lamas G, Flaker G, Mitchell $G$ and the SAVE trial investigators. Effect of Infarct Artery Patency on Prognosis After Acute Myocardial Infarction. Circulation, 1995;92(5):1101-9.

9. Centurión $O$. The open artery hypothesis: beneficial effects and long-term prognostic importance of patency of the infarct-related coronary artery. Angiology, 2007;58(1):34-44.

10. Roffi M, Patrono C, J. Collet, et al. ESC Guidelines for the management of acute coronary syndromes in patients presention withpout persistent ST-segment elevation. Eur Heart J, 2015;37(3):267-315.

11. Bangalore $S$ and Faxon DP. Coronary Intervention in Patients With Acute Coronary Syndrom: Does Every Culprit Lesion Require Revascularization? Current Cardiology Report, 2010;12(3):330-7.

12. Muller D, Topol E, Ellis $S$, et al. Multivessel coronary artery disease: a key predictor of short-term prognosis after reperfusion therapy for acute myocardial infarction. Thrombolysis and Angioplasty in Myocardial Infarction (TAMI) Study Group. Journal of American Cardiology, 1991;121(4):1042-9.

13. Goldstein G, Demetriou D, Grines C, et al. Multiple complex coronary plaques in patients with acute coronary infarction. $\mathrm{N}$ Engl J of Med, 2000;343(13):915-22.

14. Jaski B, Cohen J, Trausch J, et al. Outcome of urgent percutaneous transluminal coronary angioplasty in acute myocardial infarction: a comparison of single-vessel versus multivessel coronary artery disease. Am Heart J, 1992;124(6):1427-33. 
15. Sorajja P, Gersch B, Cox D, et al. Impact of Multivessel disease on reperfusion success and clinical outcomes in patients undergoing primary percutaneous coronary intervention for acute myocardial infarction. Eur Heart J, 2007;28(14):1709-16.

16. Mozid A, Mohdnazri S, Mannakkara N, et al. Impact of a chronic total occlusion in a non-infarct related artery on clonical outcomes following primary percutaneous intervention for acute ST-elevation myocardial infarction. J Invasive Cardiol, 2014;26(1):13-6.

17. Brener S, Mintz G, Cristea E, et al. Characteristics and clinical significance of angiographivally mild lesions in acute coronary syndromes. JACC: Cardiovascular Imaging, 2012;5(3):86-94.

18. Wu X, Maehara A, Mintz G, et al. Virtual Histology ultrasound analysis of non-culprit attenuated plaques detected by grayscale intravascular ultrasound in patients with acute coronary syndromes. Am J Cardiol, 2010;105(1):48-53.

19. Corpus R, House G, Marso S, et al. Multivessel percutaneous coronary intervention in patients with multivessel disease and acute myocardial infarction. Am Heart J, 2004;148(3): 493-500.

20. Grines C, Topol E, Califf R, et al. Prognostic implicationsand predictors of enhanced regional wall motion of the noninfarctzone after thrombolysis and angioplasty therapy of acutemyocardial infarction. The TAMI Study Group. Circulation, 1989;80(2):245-53.

21. Gibson C, Ryan K, Murphy S, et al. Impaired coronary blood flow in nonculprit arteries in the setting of acute myocardial infarction. The TIMI Study Group. Thrombolysis in myocardialinfarction. J Am Coll Cardiol, 1999;34(4):974-82.

22. Bagai $A$, Thavendi $P$, Sharieff $W$, et al. Non-infarct-related artery revascularization during primary percutaneous coronary intervention for ST-segment elevation myocardial infarction: A systematic review and meta-analysis. Am Heart J, 2013;166(4):684-93.e1.

23. Rasoul S, van Ommen V, Vainer J, et al. Multivessel revascularisation versus infarct-related artery only revascularisation during the index primary $\mathrm{PCI}$ in STEMI patients with multivessel disease: a meta-analysis. Neth Heart J, 2015;23(4):224-31.

24. Bainey K, Mehta S, Lai T, et al. Complete vs culprit-only revascularization for patients with multivessel disease undergoing primary percutaneous coronary intervention for ST-segment elevation myocardial infarction: A systematic review and meta-analysis. Am Heart J, 2014;167(1):1-14.e2.

25. Vlaar P, Mahmoud K, Holmes DJ, et al. Culprit vessel only versus multivessel and staged percutaneous coronary intervention for multivessel disease in patients multivessel disease in patients presenting with ST-segment elevation myocardial infarction: A pairwise and network meta-analysis. J Am Coll Cardiol, 2011;58(7):692-703.

26. Vogel B, Mehta S and Mehran R. Reperfusion strategies in acute myocardial infarction and multivessel disease. Nature reviews. Cardiology, 2017;14(11):665-78.

27. Cavender M, Milford-Beland S, Roe M, et al. Prevalence, predictors, and in-hospital outcomes of non-infarct artery intervention during primary percutaneous coronary intervention for ST-segment elevation myocardial infarction (from the National Cardiovascular Data Registry). Am J Cardiol, 2009;104(4):507-13.

28. Qarawani D, Nahir M, Abboud M, et al. Culprit only versus completecoronary revascularization during primary $\mathrm{PCl}$. Int $\mathrm{J}$ Cardiol, 2008;123(3):288-92.

29. Bangalore S, Kumar S, Poddar K, et al. Meta-analysis of multivessel coronary artery revascularization versus culprit-only revascularization in patients with ST-segment elevation myocardial infarction and multivessel disease. Am J Cardiol, 2011;107(9):1300-10.

30. Politi L, Sgura F, Rossi R, et al. A randomised trial of target-vessel versus multi-vessel revascularisation in ST-elevation myocardial infarction: major adverse cardiac events during long-term follow-up. Heart, 2010;96(9):662-7.

31. Wald D, Morris $\mathrm{J}$, Wald $\mathrm{N}$, and the PRAMI Investigators Randomized trial of preventive angioplasty in myocardial infarction. N Engl J Med, 2013;369(12):1115-23.
32. Gershlick A, Khan J, Kelly D and the CVLPRIT Investigarors. Randomized trial of complete versus lesion-only revascularization in patients undergoing primary percutaneous coronary intervention for STEMI and multivessel disease: the CVLPRIT trial. J Am Coll Cardiol, 2015; 65(10):963-72.

33. Engstrom T, Kelbaek H, Helqvist $\mathrm{S}$ and DANAMI-PRIMULTI Investigators. Complete revascularisation versus treatment of the culprit lesion only in patients with ST-segment elevation myocardial infarction and multivessel disease (DANAMI-3-PRIMULTI): an open-label, randomised controlled trial. Lancet, 2015;386(9994):665-71.

34. Smits P,Abdel-Wahab M, Neumann F, and the Compare-Acute Investigators. Fractional flow reserve-guided multivessel angioplasty in myocardial infarction. N Engl J Med, 2017;376(13):1234-44.

35. Mehta S, Wood D and Storey R. Complete Revascularization with Multivessel PCl for Myocardial Infarction. N Engl J Med, 2019;15(381):1411-21.

36. Mehta S, Wood D, Meeks B, et al. Design and rationale of the COMPLETE trial: A randomized, comparative effectiveness study of complete versus culprit-only percutaneous coronary intervention to treat multivessel coronary artery disease in patients presenting with STEMI. Am Heart J, 2019;215(0):157-66.

37. Bates E, Tamis-Holland J, Bittl J, et al. PCI Strategies in Patients With ST-Segment Elevation Myocardial Infarction and Multivessel Coronary Artery Disease. Am Coll Cardiol. 2016;68(10):1066-81.

38. Hanratty $\mathrm{C}$, Koyama $\mathrm{Y}$, Rasmussen $\mathrm{H}$, et al. Exaggeration of nonculprit stenosis severity during acute myocardial infarction: Implications for immediate multivessel revascularization. J Am Coll Cardiol, 2002;40(5):911-16.

39. Uren N, Crake T, Lefroy D, et al. Reduced coronary vasodilator function in infarcted and normal myocardium after myocardial infarction. N Engl J Med, 1994;331(4):222-27.

40. Ntalianis A, Sels J, Davidavicius G, et al. Fractional flow reserve for the assessment of nonculprit coronary artery stenoses in patients with acute myocardial infarction. JACC Cardiovasc Interv, 2010;3(12):1274-81.

41. Anand $S$, Islam $S$, Rosengren $A$ and the INTERHEART Investigators. Risk factors for myocardial infarction in women and men: insights from the INTERHEART study. Eur Heart J, 2008;29(7):932-40.

42. Lozano R, Naghavi M, Foreman K, et al. Global and regional mortality from 235 causes of death for 20 age groups in 1990 and 2010: a systematic analysis for the Global Burden of Disease Study. Lancet, 2012;380(9859):2095-128.

43. Shafey O, Eriksen M, Ross $\mathrm{H}$, at al. The Tabacco Atlas. Atlanta, American Cancer Society, 2009.

44. Национален статистически институт. Здравеопазване 2017. София, Национален статистичести институт, 2017.

45. Kristensen S, Laut K, Fajade J, et al. Reperfusion therapy for ST elevation acute myocardial infarction 2010/2011: current status in 37 ESC countries. Eur Heart J, 2014; 35(29):1957-70.

46. Байрактарова И, Насева E, Трендафилова E, Александров А, Банкова А, Богов И, Георгиева С, Григоров В, Димитрова Е, Йорданова X, Костова Е, Матеев X, Петрова И, Христова Г, Тасовска П и Гочева Н. Разлики в рисковия профил на пациентите c NSTEMI спрямо пациентите със STEMI в българска популация. Българска кардиология, 2018;24(Приложение 5):19-20.

47. Karamfiloff K, Stoykova J and Georeva P. Multivessel disease as a prognostic factor for mortality in STEMI patients. J Biomed Clin Res, 2015;8(1):30-4.

48. Karamfiloff K, Vassilev D, Staneva M. Prognostic factors for early mortality in STEMI patients treated with primary $\mathrm{pPCl}$. Comptes rendus de l'Académie bulgare des sciences: sciences mathématiques et naturelles, 2015;68(7):935-40.

49. Йорданова X, Григоров В, Трендафилова Е, Димитрова Е, Александров А, Матеев Х, Банкова А, Тасовска П, Георгиев Б и Гочева Н. Предиктори за развитие на остра сърдечна недостатъчност след проведена първична ПКИ при пациенти със STEMI. Българска кардиология, 2018;24(Приложение 5):20. 